\title{
Induction of Diploid Eggs With Colchicine During Embryo Sac Development in Populus
}

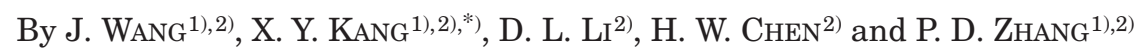

(Received 22 $2^{\text {nd }}$ August 2009)

\begin{abstract}
Diploid ( $2 n$ ) eggs were induced by treating developing embryo sacs of Populus with colchicine solution, in order to produce triploid plants. The optimal pollinated time of female catkins was confirmed as timing point for each treatment. When female catkins of $P$. pseudo-simonii $\mathrm{x}$ $P$. nigra 'Zheyin3\#' had become $5.62 \pm 0.13 \mathrm{~cm}$ long $84 \mathrm{~h}$ after they emerged from their bract scales and all stigmas were exposed, pistils all over the entire catkin had optimal stigma receptivity. Observation of paraffin sections showed that embryo sac development of 'Zheyin3\#', which initiated $12 \mathrm{~h}$ before pollination and finished $132 \mathrm{~h}$ after pollination, was a successive and asynchronous process. Generative cell division of pollen of the male parent $P$. $x$ beijingensis took place $3-16 \mathrm{~h}$ after pollination. Catkins of 18-96 h after pollination of 'Zheyin3\#' were treated with colchicine solution. In the progeny, twenty three triploids were detected by chromosome counting and the highest rate of triploids was $66.7 \%$ in one treatment. The rate of triploid yield was positively correlated with the frequency of four-nucleate embryo sacs $(r=0.6721, p=0.0981)$ and was not significantly correlated with the percentages of uni-, twoand eight-nucleate embryo sac $(r=-0.1667, p=0.7210$, $r=-0.3069, p=0.5031$ and $r=0.0189, p=0.9679$, respectively), suggesting that the third mitotic division of embryo sac may be the effective stage to induce $2 n$ eggs. Through this approach, completely homozygous $2 n$ eggs can be produced. Its significance for plant breeding is discussed.
\end{abstract}

Key words: $2 n$ egg, colchicine, embryo sac development, Populus, triploid.

\section{Introduction}

The genus Populus, as an important source of fuel, fibre and lumber, is widely distributed and cultivated over the northern hemisphere (RAE et al., 2007). Some triploid cultivars of Populus have many desirable properties in growth and pulpwood characteristics compared to diploids (VAN BUIJTENEN et al., 1958; EINSPAHR et al., 1972; ZHU et al., 1995). Thus, triploid breeding is one of the most powerful approaches for improvement of Populus.

Diploid (2n) gametes are usually applied to produce triploids of Populus. There are many investigations on

\footnotetext{
1) National Engineering Laboratory for Tree Breeding, Beijing Forestry University, 100083, Beijing, P. R. China.

$\left.{ }^{2}\right)$ Key Laboratory of Genetics and Breeding in Forest Trees and Ornamental Plants, Ministry of Education, Beijing Forestry University, 100083, Beijing, P.R. China.

*) Address correspondence to: P.O. Box 118, Beijing Forestry University, 100083, Beijing, P.R. China; Tel.: +86-10-62336104; E-Mail: kangxy@bju.edu.cn
}

induction of $2 n$ pollen, due to easy screening by their size. JoHNSSON and EKLUNDH (1940) first induced $2 n$ pollen of $P$. tremula and $P$. tremuloides with colchicine, and produced triploid plants by pollinating to female catkins of diploid plants with the artificial $2 n$ pollen. So far, more triploids have been obtained by crossing with induced $2 n$ pollen in $P$. deltoides, $P$. alba, $P$. tomentosa and other white poplars (MASHKINA et al., 1989; ZHANG and LI, 1992; KANG et al., 2000), and the pachytene stage of microsporogenesis is proved as the optimal stage for $2 n$ pollen induction with colchicine. Although the percentage of artificial $2 n$ pollen can be upward of 80\% (ZHANG and LI, 1992; KANG et al., 1999), the effect of triploid production is not good because of competition from normal pollen (KANG and ZHU, 1997; KANG, 2002).

Compared with $2 n$ pollen, triploid production via $2 n$ eggs may be more suitable. However, reports on induction of $2 n$ eggs are rare in Populus, because it is difficult to timely determine the exact stage of megasporogenesis, which progresses in the inside of ovules. Based on the temporal relationship between megasporogenesis and microspore development under similar cultured conditions in P. alba x P. glandulosa, LI et al. (2008) obtained 12 triploids by inducing unreduced megaspores with a $0.5 \%$ colchicine solution at the prophase of the first meiotic division, and the highest rate of produced triploids in one treatment was $16.7 \%$. It is well known that functional megaspore develops into mature female gametophyte after megasporogenesis, i.e. megagametogenesis (also called embryo sac development). In this process, the megaspore undergoes at least one round of mitosis without cytokinesis. For Populus, the embryo sac development complies with Polygonum type, in which a 7-celled mature embryo sac formation initiated from a functional megaspore via three rounds of mitotic division (NAGARAJ, 1952; KIMURA, 1955, 1963; Li et al., 1982; Li and ZHU, 1988; ZHU and LI, 1989; DoNG, 1984; FAN, 1984; LI and MA, 2006). Potentially, these mitotic divisions offer us the possibility to induce $2 n$ eggs.

Colchicine is an alkaloid that contributes to the prevention of tubulin polymerization, thereby arresting formation of spindle and restraining nuclear division at metaphase (JORDAN and WILsON, 1999). Consequently, colchicine has been widely used to induce polyploids in plants (EIGSTI and Dustin, 1955). In polyploid breeding programs of the genus Populus, colchicine is the most commonly used reagent and has good effects (JOHNSSON and EKLUNDH, 1940; EINSPAHR, 1965; KANG et al., 1999, 2004; LI et al., 2008). In our investigation, female catkins of $P$. pseudo-simonii x P. nigra 'Zheyin3\#' under embryo sac development were treated with colchicine solution, in order to discuss the possibility of $2 n$ egg 
induction and to serve to triploid breeding programs of the genus Populus.

\section{Materials and Methods}

\section{Plant materials}

Female floral branches of $P$. pseudo-simonii $\times$ P. nigra 'Zheyin3\#' (female parent, $2 n=2 x=38$ ) were collected from a plantation in Tongliao City (Inner Mongolia Autonomous Region, P. R. China). Male floral branches of $P$. $\mathrm{x}$ beijingensis (male parent, $2 n=2 x=38$ ) were collected from the campus of Beijing Forestry University.
The branches were cultured in a greenhouse $\left(10-20^{\circ} \mathrm{C}\right)$ for later use.

\section{Determination of optimal stigma receptivity}

Female catkins were selected to examine stigma receptivity of 'Zheyin3\#' every $6 \mathrm{~h}$, starting with the catkins emerging from bract scales. Lengths of the catkins and colour of their stigmas were recorded. For each time, the lengths of 10 catkins were measured with a vernier caliper. The catkins were hand-pollinated with fresh pollen of $P . \times$ beijingensis. Four hours after pollination, the catkins were fixed in FAA ( $70 \%$ ethanol: acetic
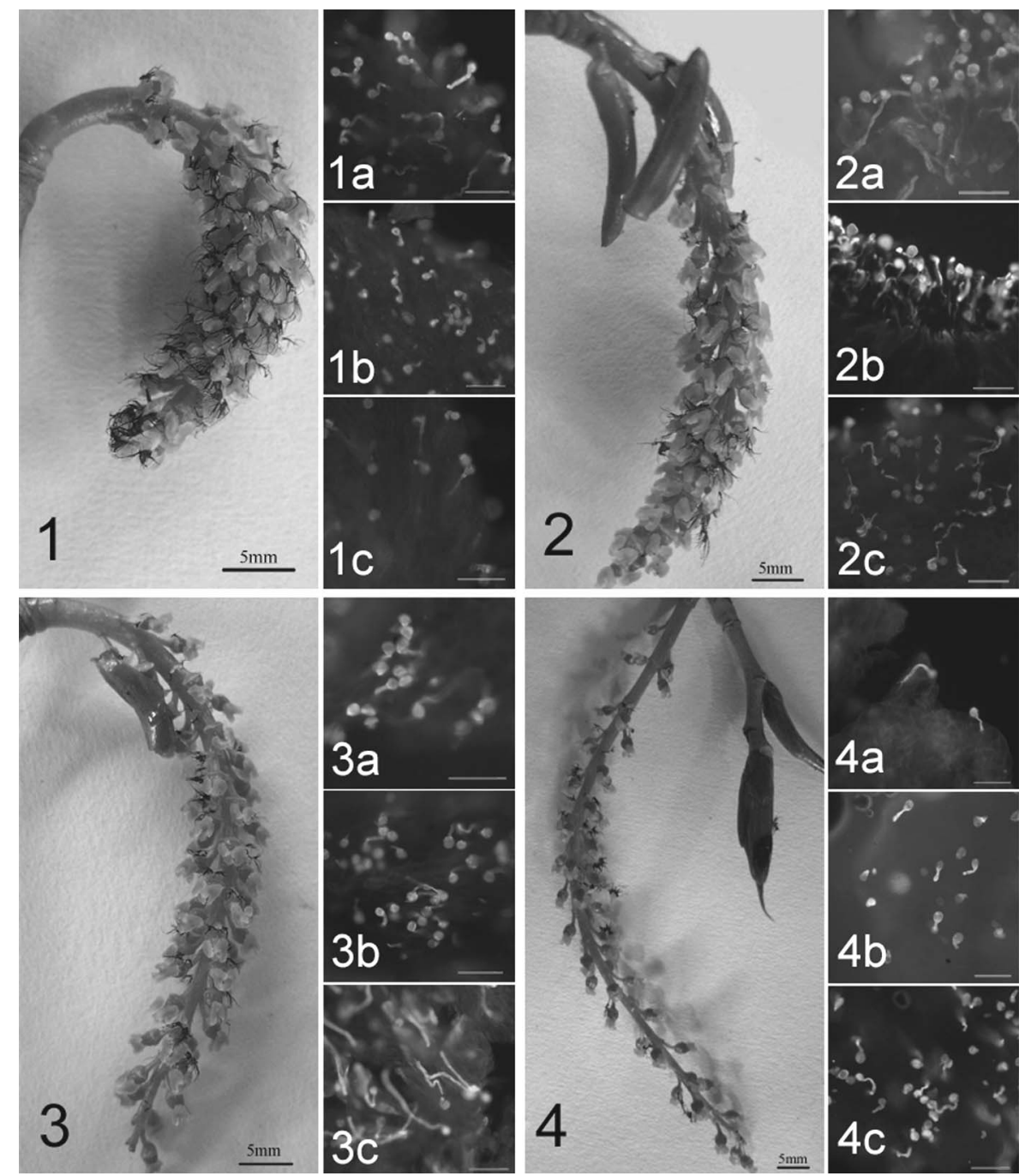

Figure 1. - Stigma receptivity of $P$. pseudo-simonii x P. nigra 'Zheyin3\#'. Lower-case letters $\mathrm{a}, \mathrm{b}$ and $\mathrm{c}$ show pollen germination on stigmas at base, middle and top of catkins respectively. Unmarked bars are equal to $100 \mu \mathrm{m}$.

Fig. 1: Catkin before optimal pollinated time. Normal pollen germination on basal and middle stigmas ( $1 \mathrm{a}$ and $1 \mathrm{~b}$ ). Only a few pollen grains germinated on the top stigmas (1c).

Fig. 2: Catkin at optimal pollinated time. Vigorous pollen germination on stigmas at different parts of the catkin.

Fig. 3: Catkin after optimal pollinated time. Pollen germination on the basal stigmas (3a) is not as good as that on the middle and top stigmas (3b and 3c).

Fig. 4: Catkin with retained receptivity. No receptivity on the basal stigmas (4a), tardy germination on the middle stigmas $(4 \mathrm{~b})$ and relatively normal germination on the top stigmas (4c). 
acid: $40 \%$ formaldehyde, 90:5:5) for $24 \mathrm{~h}$ at $4{ }^{\circ} \mathrm{C}$. After being washed with distilled water, the stigmas at the top, middle and base of each fixed catkin were respectively softened in $8 \mathrm{M} \mathrm{NaOH}$ for $2 \mathrm{~h}$. Following further washing in distilled water, the flowers were squashed in $0.1 \%$ aniline blue and stained for $10 \mathrm{~min}$. The preparations were observed under a fluorescence microscope (Olympus BX51).

\section{Observation of generative cell division in pollen}

The development of generative cells was studied in vivo. Pollen grains of $P$. $\mathrm{x}$ beijingensis were pollinated to stigmas with optimal receptivity of the female parent. The stigmas were fixed in FAA every $2 \mathrm{~h}$ for $24 \mathrm{~h}$ at $4{ }^{\circ} \mathrm{C}$, starting from being pollinated until $48 \mathrm{~h}$ after pollination. Subsequently, they were softened in $8 \mathrm{M} \mathrm{NaOH}$ for at least $12 \mathrm{~h}$. After being washed in distilled water, the samples were squashed in one drop of 4',6-diamidino-2phenylindole (DAPI) and stained for $10 \mathrm{~min}$. The devel- opment of generative cells was examined under the above fluorescence microscope.

\section{Determination of developmental process of embryo sacs}

The female buds and catkins of 'Zheyin3\#' were fixed in FAA at $4{ }^{\circ} \mathrm{C}$ every $12 \mathrm{~h}$ after being cultured and every $6 \mathrm{~h}$ after pollination, until maturation of seeds. Ovaries from each fixed buds and catkin were embedded with paraffin and sectioned at 8-10 $\mu \mathrm{m}$. The sections were stained with iron-hematoxylin and observed under the microscope. During the embryo sac development, a total of 1,470 sacs were analyzed in order to reveal the process of embryo sac development.

\section{Induction of $2 n$ eggs}

When female catkins acquired the optimal receptivity, they were pollinated with fresh collected pollen of $P . \mathrm{x}$ beijingensis. Based on the process of the embryo sac development of 'Zheyin3\#', the female catkins 18-96 h


Figure 5. - Generative cell division of $P . \times$ beijingensis in vivo. Two-celled pollen (a), mitotic metaphase (b), anaphase (c) and two formed sperms in tube (d). Bars are equal to $10 \mu \mathrm{m}$.



Figure 6. - Embryo sac development and fertilization of P. pseudo-simonii $\mathrm{x}$ $P$. nigra 'Zheyin3\#'. The chalazal end is at the top in all figures. a, Uni-nucleate embryo sac with three degenerated megaspores. b, Two-nucleate embryo sac. c, Four-nucleate embryo sac. d-e, Mature embryo sac including three antipodal cells (d), one secondary nucleus and one egg apparatus (e). One of the synergid cells is out of focus. f, Fertilization. The arrow shows one sperm is close to egg. Bars are equal to $10 \mu \mathrm{m}$. 
after pollination were immersed in $0.3-0.5 \%$ colchicine solution for $18-30 \mathrm{~h}$. In view of the weak colchicine-tolerance of catkins soon after pollination, both $0.3 \%$ and $0.5 \%$ colchicine solution were used to treat the catkins during $18 \mathrm{~h}$ to $42 \mathrm{~h}$ after pollination. After treatment, the colchicine was rinsed away under taps. The catkins without treatment were set as the control group. After the catkins matured, seeds were collected and germinat-

Table 1. - Process of embryo sac development in P. pseudo-simonii x P. nigra 'Zheyin3\#'.

\begin{tabular}{|c|c|c|c|c|c|c|c|}
\hline \multirow{2}{*}{$\begin{array}{l}\text { Hours after } \\
\text { pollination }\end{array}$} & \multicolumn{7}{|c|}{ Percentage of each stage (\%) } \\
\hline & Meiosis & Tetrad & $\begin{array}{l}\text { Uni-nucleate } \\
\text { embryo sac }\end{array}$ & $\begin{array}{l}\text { Two-nucleate } \\
\text { embryo sac }\end{array}$ & $\begin{array}{l}\text { Four-nucleate } \\
\text { embryo sac }\end{array}$ & $\begin{array}{l}\text { Eight-nucleate and } \\
\text { mature embryo sac }\end{array}$ & $\begin{array}{l}\text { Fertilization } \\
\text { and post }\end{array}$ \\
\hline-12 & 24.36 & 47.44 & 28.21 & & & & \\
\hline 0 & 6.58 & 14.47 & 56.58 & 22.37 & & & \\
\hline 6 & & 1.92 & 59.62 & 31.73 & 6.73 & & \\
\hline 12 & & 9.80 & 68.63 & 15.69 & 5.88 & & \\
\hline 18 & & 1.92 & 46.15 & 36.54 & 13.46 & 1.92 & \\
\hline 24 & & 6.38 & 44.68 & 31.91 & 17.02 & & \\
\hline 30 & & & 11.27 & 32.39 & 25.35 & 30.99 & \\
\hline 36 & & & 4.94 & 28.40 & 29.63 & 37.04 & \\
\hline 42 & & & 13.04 & 31.88 & 26.09 & 28.99 & \\
\hline 48 & & & 10.00 & 38.00 & 28.00 & 24.00 & \\
\hline 54 & & & 7.58 & 15.15 & 40.91 & 36.36 & \\
\hline 60 & & & 7.94 & 12.70 & 46.03 & 33.33 & \\
\hline 66 & & & 3.57 & 8.93 & 41.07 & 46.43 & \\
\hline 72 & & & 2.22 & 13.33 & 28.89 & 55.56 & \\
\hline 78 & & & & 14.55 & 34.55 & 50.91 & \\
\hline 84 & & & & 10.00 & 21.67 & 63.33 & 5.00 \\
\hline 90 & & & & 11.36 & 22.73 & 59.09 & 6.82 \\
\hline 96 & & & & 1.45 & 17.39 & 59.42 & 21.74 \\
\hline 102 & & & & 1.67 & 3.33 & 50.00 & 45.00 \\
\hline 108 & & & & 7.41 & 18.52 & 44.44 & 29.63 \\
\hline 114 & & & & 2.70 & 10.81 & 21.62 & 64.86 \\
\hline 120 & & & & & 10.81 & 27.03 & 62.16 \\
\hline 126 & & & & & 12.82 & 25.64 & 61.54 \\
\hline 132 & & & & & 4.26 & 34.04 & 61.70 \\
\hline 138 & & & & & & 28.57 & 71.43 \\
\hline 144 & & & & & & 25.00 & 75.00 \\
\hline
\end{tabular}


ed in soil. When the seedlings grew to about $30 \mathrm{~cm}$ in height, they were transplanted to the field.

\section{Analysis of ploidy level}

The determination of the ploidy level was conducted by somatic chromosome counting. Stem tips were removed from the seedlings and pretreated with a saturated solution of paradichlorobenzene for $4 \mathrm{~h}$ at $25^{\circ} \mathrm{C}$. Subsequently, the materials were fixed in a fresh Carnoy solution (ethanol: acetic acid, 3:1) for $24 \mathrm{~h}$ at $4{ }^{\circ} \mathrm{C}$. The fixed materials were then hydrolyzed in a mixed fluid of $38 \% \mathrm{HCl}$ and ethanol (1:1) for $25 \mathrm{~min}$ at room temperature. After being washed in distilled water three times for $15 \mathrm{~min}$, the hydrolyzed materials were squashed heavily in a Carbol Fuchsin solution. Chromosome counting was carried out under the Olympus BX51. At least 20 cells with a well-spread metaphase from each seedling were observed.

\section{Results}

\section{Stigma receptivity of 'Zheyin3\#'}

The stigma receptivity of 'Zheyin3\#' lasted 3-4 d. The receptivity among pistils in different parts of catkin varied. The pistils at the base of the catkin were the first to acquire stigma receptivity and were also the first to lose it; the pistils at the top of the catkin acquired it at last but were also the last to lose it.

Sixty hours after the catkins emerged from their bract scales, they developed into $3.45 \pm 0.06 \mathrm{~cm}$ long. All stigmas in the catkins were green-yellow in colour. Bracts of basal pistils evaginated and stigmas were exposed. After pollination, pollen germination was observed on the basal stigmas. However, stigmas at the middle and top of the catkins, covered under bracts, had not acquired receptivity. Twelve hours later, the catkins were $4.23 \pm 0.13 \mathrm{~cm}$ in length. Except for the top stigmas, the middle and basal stigmas had both emerged from their bracts (Fig. 1). Pollen germination tests showed that the stigmas at the middle and base of the catkins both had receptivity (Figs. $1 a$ and $b$ ). Only a few pollen grains with little germination adhered to the top stigmas (Fig. 1c). With their development, the catkins elongated to $5.62 \pm 0.13 \mathrm{~cm}$ long $84 \mathrm{~h}$ after they emerged from their bract scales. All bracts turned inside out, some even were shed. At this stage, all stigmas were exposed (Fig. 2). Pollen germination tests showed that plenty of pollen germinated vigorously on all stigmas at different parts of the catkins (Figs. $2 a, b$ and $c$ ), which indicated that the catkins acquired the optimal stigma receptivity. Therefore, this time was the optimal pollinated time. When the catkins developed to $6.27 \pm 0.10 \mathrm{~cm}$ in length $102 \mathrm{~h}$ after they emerged from their bract scales, they began to become less incompact (Fig. 3). Although pollen grains still germinated on all stigmas, the number of germinated pollen grains on the basal stigmas was less than that on the middle and top stigmas (Figs. $3 a, b$ and $c$ ). Five to six days after they emerged from their bract scales, the catkins relaxed completely and were $10.26 \pm 0.18 \mathrm{~cm}$ long (Fig. 4). The basal stigmas became yellow-green in colour with a little brown. Only a few pollen grains clung to the stigmas and germinated (Fig.
$4 a)$. The middle and top stigmas were still green-yellow. Pollen germination on the middle and top stigmas was better than on the basal stigmas, but not flourishing (Figs. $4 b$ and $c$ ). Seven days after they emerged from their bract scales, all stigmas at the catkins became brown and pollen no longer germinated.

\section{Division of generative cells in pollen of $P$. $x$ beijingensis}

Mature pollen grains of $P$. $x$ beijingensis were of the 2 celled type (Fig. 5a). In vivo, pollen grains started to germinate on the stigmas of 'Zheyin3\#' $2 \mathrm{~h}$ after pollination. Generative cell division occurred $3-16 \mathrm{~h}$ after pollination (Figs. $5 b$ and $c$ ). Two sperm cells were formed 12-18 h after pollination (Fig. $5 d$ ).

\section{Development of embryo sacs}

Embryo sac development of 'Zheyin3\#' was of the typical Polygonum type. Functional megaspore formed a 7celled mature embryo sac via three rounds of mitotic divisions (Fig. 6). The mature embryo sac consisted of two synergid cells, an egg cell, a central cell and three antipodal cells (Figs. 6d and $e$ ).

The embryo sac development was a successive and asynchronous process (Table 1). It was initiated $12 \mathrm{~h}$ before pollination. Three micropylar megaspores of a tetrad began to degenerate and the enlarged functional megaspore at the chalazal end formed a uni-nucleate embryo sac (Fig. 6a). Until $24 \mathrm{~h}$ after pollination, the uni-nucleate embryo sac was dominant, although other stages, such as the tetrad, the two-nucleate embryo sac (Fig. 6b), the four-nucleate sac (Fig. 6c) and even the eight-nucleate sac (Figs. $6 d$ and $e$ ), were also observed. Thirty to forty-eight hours after pollination, the proportion of the two-nucleate embryo sac was predominant. With the development of embryo sacs, the rate of the four-nucleate embryo sac increased gradually. Its percentage was greater than that of other stages 54-60 h after pollination. After that, all cells developed into eight-nucleate and mature embryo sacs in succession. Fertilization occurred between $84 \mathrm{~h}$ and $144 \mathrm{~h}$ after pollination (Fig. 6f).

\section{Production of triploids}

Table 2 shows that a total of 23 triploids $(2 n=3 x=57$, Fig. $7 a$ ) were obtained by treating pollinated catkins of 'Zheyin3\#', under embryo sac development. In some

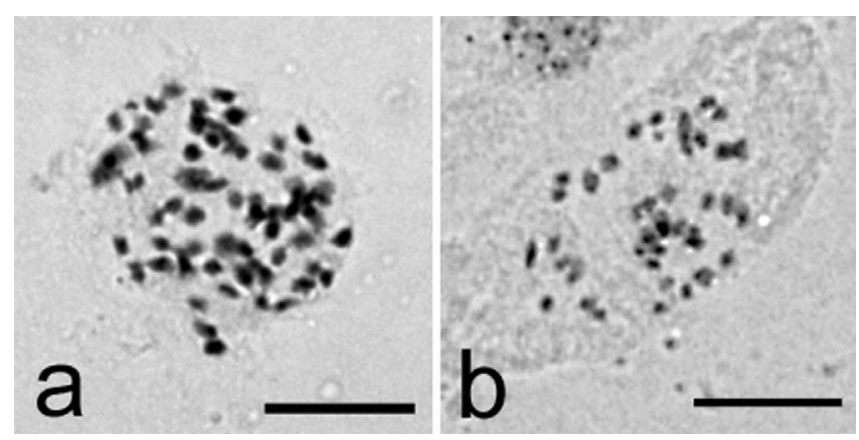

Figure 7. - Number of Chromosomes of diploid and triploid progenies. Fifty seven chromosomes in triploid (a) and thirty eight in diploid (b). Bar is equal to $10 \mu \mathrm{m}$. 
Table 2. - Triploid production through treating developing embryo sacs of P. pseudo-simonii $\times$ P. nigra 'Zheyin3\#' with colchicine solution.

\begin{tabular}{|c|c|c|c|c|c|c|c|}
\hline No. & $\begin{array}{l}\text { Hours after } \\
\text { pollination }\end{array}$ & $\begin{array}{l}\text { Concentration of } \\
\text { colchicine }(\%)\end{array}$ & $\begin{array}{l}\text { Duration of } \\
\text { treatment (h) }\end{array}$ & $\begin{array}{l}\text { Number } \\
\text { of seeds }\end{array}$ & $\begin{array}{l}\text { Number of } \\
\text { seedlings }\end{array}$ & $\begin{array}{l}\text { Number of } \\
\text { triploids }\end{array}$ & $\begin{array}{c}\text { Rate of } \\
\text { triploids (\%) }\end{array}$ \\
\hline 1 & 18 & 0.3 & 24 & 23 & 0 & - & - \\
\hline 2 & 24 & 0.3 & 24 & 208 & 49 & 2 & 4.08 \\
\hline 3 & 30 & 0.5 & 24 & 0 & - & - & - \\
\hline 4 & 36 & 0.3 & 24 & 27 & 3 & 0 & 0 \\
\hline 5 & 42 & 0.5 & 24 & 4 & 0 & - & - \\
\hline 6 & 48 & 0.5 & 24 & 13 & 0 & - & - \\
\hline 7 & 54 & 0.5 & 18 & 19 & 9 & 1 & 11.11 \\
\hline 8 & 54 & 0.5 & 30 & 137 & 74 & 7 & 9.46 \\
\hline 9 & 60 & 0.5 & 18 & 78 & 6 & 4 & 66.67 \\
\hline 10 & 66 & 0.5 & 30 & 80 & 35 & 7 & 20.00 \\
\hline 11 & 72 & 0.5 & 24 & 41 & 7 & 1 & 14.29 \\
\hline 12 & 84 & 0.5 & 24 & 0 & - & - & - \\
\hline 13 & 96 & 0.5 & 24 & 83 & 14 & 1 & 7.14 \\
\hline Control & & & & 345 & 118 & 0 & 0 \\
\hline Total & & & & 1058 & 315 & 23 & \\
\hline
\end{tabular}

treatments, no seedlings survived. All seedlings in the control group were confirmed as diploid $(2 n=2 x=38$, Fig. $7 b$ ). Nineteen triploids were produced in the treatments $54-66 \mathrm{~h}$ after pollination, representing $82.6 \%$ of the total number of triploids. The highest rate of triploids in one treatment was $66.7 \%$, which occurred 60 $\mathrm{h}$ after pollination.

Correlation analyses were made between the efficiency of triploid production and percentage of each developmental stage of embryo sac (Fig. 8). A moderate positive correlation was found between the rate of triploids and the percentage of four-nucleate embryo sacs $(r=0.6721$, $p=0.0981)$. However, there were no significant correlations between the rate of triploids and the percentages of uni-, two- and eight-nucleate embryo sacs $(r=-0.1667, p=0.7210, r=-0.3069, p=0.5031$ and $r=0.0189, p=0.9679$, respectively).

\section{Discussion}

Pollination at the right time is the basis for successful hybridization. Stigma receptivity is an important factor affecting effective pollination, which is related to seed yield (EGEA et al., 1991; SANZOL and Herrero, 2001). Estimation of $2 n$ egg production relies on the polyploid yield in progeny. Therefore, exact pollination should be emphasized. In the present study, the optimal stigma receptivity of catkin of 'Zheyin3\#' was identified, which insured successful hybridization and reliable seed set. Furthermore, treatment of $2 n$ egg induction is based on timely determination of stage of embryo sac development, but it is difficult to detect because of its location inside of ovule. In view of the result that the embryo sac development of 'Zheyin3\#' almost undertook after pollination, the optimal pollinated time was useful to be regarded as a reference point for each treatment in this investigation.

There are two types of mature pollen in plants, i.e. 2celled and 3-celled types. For 2-celled pollen, division of generative cell occurs in pollen tube after germination. EINSPAHR (1965) unexpectedly obtained some putative triploids when he treated catkins in $6-30 \mathrm{~h}$ after pollination in order to induce tetraploids by treating newly formed embryos of quaking aspen with colchicine. WINTON (1968) explained that production of these triploids was caused by an unreduced division of generative cell in pollen tube. In our investigation, however, the generative cell of pollen of male parent $P$. $x$ beijingensis divided 3-16 $\mathrm{h}$ after pollination, which did not coincide with the effective period of triploid production. It suggests 

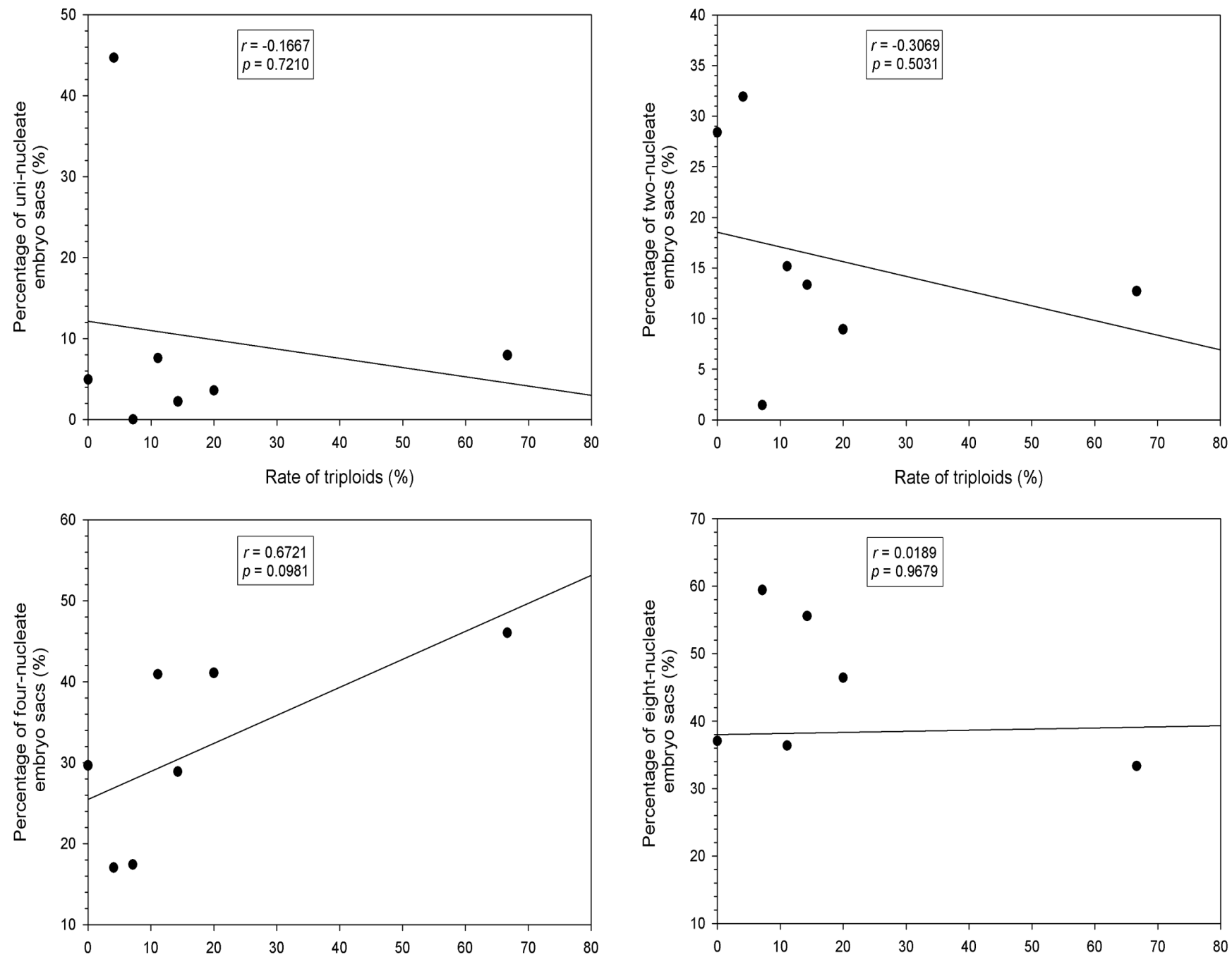

Figure 8. - Correlation analyses between rate of triploids and percentage of each embryo sac developmental stage.

that the triploids in this study are not from fertilization of diploid generative cell.

In the genus Populus, induction of $2 n$ gametes has, so far, focused on the meiotic process. Prophase I is an efficient stage to induce $2 n$ gametes. For pollen chromosome doubling, the percentage of $2 n$ pollen can be upward of $80 \%$ by treating with colchicine (ZHANG and LI, 1992; KANG et al., 1999). However, it is not compatible between the high percentage of $2 n$ pollen and the rate of triploid production by pollinating with them, owing to the weak competitive ability of $2 n$ pollen compared with normal pollen in germination and fertilization (KANG and ZHU, 1997; KANG, 2002). The highest rate of triploid production by pollinating with $2 n$ pollen was just $12.9 \%$, even though the $2 n$ pollen had been treated by $\gamma$-irradiation to enhance their competitive ability (KANG et al., 2000). For female gamete chromosome doubling, the effect just can be estimated by polyploidy production in progeny. LI et al. (2008) obtained 12 triploids by crossing with $2 n$ megaspores induced by colchicine at prophase I of megasporogenesis and the highest rate of triploid production was $16.7 \%$ in one treatment. In the present investigation, twenty-three triploids were produced by treating pollinated female catkins under embryo sac development and the highest rate was up to $66.7 \%$ in one treatment, which suggests that a novel approach for $2 n$ egg induction has been discovered and that this approach is more efficient for triploid production than both the $2 n$ pollen and $2 n$ megaspore approaches. Further more, correlation analyses showed that the rate of triploid production was positively correlated with the frequency of four-nucleate embryo sac, but not significantly correlated with both uni- and two-nucleate sacs, indicating that the third mitotic division during embryo sac development may be more effective for $2 n$ egg induction through external actions, but it can not exclude the possibility of $2 n$ egg formation by mitotic inhibition at the first or second division.

KANG et al. (2004) obtained $57.1 \%$ allotriploids of white poplar by treating female catkins with colchicine 24-36 h after pollination. However, he did not give a reasonable explanation on origin of these triploids. Additionally, when EINSPAHR (1965) treated pollinated catkins of quaking aspen to induce tetraploid, he unexpectedly screened some putative triploids. Although chromosome doubling of sperm cells is possible (WINTON, 1968), production of $2 n$ eggs during embryo sac develop- 
ment may be a better explanation for the results of the earlier studies, in view of its high efficiency.

There are three modes for polyploid formation through $2 n$ gametes, i.e. $2 n+n, n+2 n$ and $2 n+2 n$ mode. The usage of $2 n$ pollen is restricted, because it does not compete well with normal pollen (HARLAN and DEWET, 1975; KANG and ZHU, 1997). Therefore, fertilization between $2 n$ egg and $\mathrm{n}$ pollen may be the most common mode for triploid origin (HARLAN and DEWET, 1975). In general, formation of $2 n$ eggs is attributed to meiotic division restitution (PFEIFFER and BINGHAM, 1983; WERNER and Peloquin, 1987, 1990, 1991; Conicella et al., 1991; OGBURIA et al., 2002), aberrant cytokinesis (WERNER and PELOQUin, 1990), postmeiotic restitution (PMR) (BASTIAANSSEN et al., 1998) and apospory (BURSON et al., 2002). Endo-duplication of chalazal megaspore after meiosis is one explanation for the PMR mechanism (BREMER, 1959, 1963). After megasporogenesis, megaspores undergo embryo sac development to form mature megagametophyte. YAMADA and TAO (2007) suggested the possibility that $2 n$ or $3 n$ eggs could be initiated by abnormal mitosis during embryo sac development in Diospyros kaki 'Fujiwaragosho'. Our work proved that $2 n$ eggs could be produced during embryo sac development, which is a strong supplementation of the PMR mechanism.

Diploid gametes are of evolutionary importance in the origin of new polyploids (HARLAN and DEWET, 1975). The mechanism of $2 n$ gamete production was reviewed by Veilleux (1985) and BREtagnolle and Thompson (1995). Depending on the mechanism for $2 n$ gamete formation, the genetic consequences in the polyploid progeny vary. The first division restitution type $2 n$ gamete theoretically transmits approximately $80 \%$ parental heterozygosity to the progeny and the second division restitution type can transmit about $40 \%$ (MENDIBURU and Peloquin, 1977). However, different from the former types of $2 n$ gametes, completely homozygous $2 n$ gametes can arise from the PMR mechanism (BASTIAANSSEN et al., 1998). Originated from mitotic inhibition, the $2 n$ eggs induced in our investigation could be deduced to be characterized by complete homozygosity, which is promising in improvement and genetic research of trees and crops. More plants will be able to benefit from this approach. Because nearly all trees and most agricultural crops are highly heterozygous, induced parthenogenesis from the completely homozygous $2 n$ eggs is able to produce homozygous progeny. Additionally, when the $2 n$ eggs are fertilized with normal pollen to give rise to triploids, the homozygosity from the maternal genome will be helpful to analyze the dosage effect of genes.

\section{Acknowledgements}

The authors thank the Forestry Research Institute of Tongliao City, the Inner Mongolia Autonomous Region, P. R. China, for collecting the plant material and for additional help. The authors also thank Dr. G. HAZENBERG for critical reading of the manuscript. This work was supported by the National Natural Science Foundation of China (Grant No. 30671708).

\section{References}

Bastiaanssen, H. J. M., P. M. M. M. van Den Berg, P. Lindhout, E. Jacobsen and M. S. Ramanna (1998): Postmeiotic restitution in $2 n$-egg formation of diploid potato. Heredity 81: 20-27.

BREMER, G. (1959): Increase of chromosome number in species hybrids of Saccharum in relation to the embryosac development. Bibliographia Genetica 18: 1-99.

BREMER, G. (1963): Problems in breeding and cytology of sugar cane. Euphytica 12: 178-188.

BRetagnolle, F. and J. D. Thompson (1995): Gametes with the somatic chromosome number: mechanisms of their formation and role in the evolution of autopolyploid plants. New Phytol 129: 1-22.

Burson, B. L., M. A. Hussey, J. M. Actkinson and G. S. SHAFER (2002): Effect of pollination time on the frequency of $2 n+n$ fertilization in apomictic buffelgrass. Crop Sci 42: 1075-1080.

Conicella, C., A. Barone, A. Del Giudice, L. Frusciante and L. M. Monti (1991): Cytological evidences of SDRFDR mixture in the formation of $2 n$ eggs in a potato diploid clone. Theor Appl Genet 81: 59-63.

Dong, Y. (1984): Some embryological observations on Populus tomentosa Carr. II. about the structures of ovule and embryo sac, the process of fertilization and the development of embryo. J Beijing For College 1: 83-94.

EgeA, J., L. Burgos, J. E. Garcia and L. EgEA (1991): Stigma receptivity and style performance in several apricot cultivars. J Hortic Sci 66: 19-25.

Eigsti, O. J. and P. J. Dustin (1955): Colchicine in agriculture, medicine, biology, and chemistry. Iowa State College Press, Ames.

EINSPAHR, D. W. (1965): Colchicine treatment of newly formed embryos of quaking aspen. For Sci 11(4): 456-459.

Einspahr, D. W., M. K. Benson and M. L. HARder (1972): Within-tree variation in specific gravity of young quaking aspen. Genetics and Physiology Notes, Institute of Paper Chemistry, U.S., 13: 8.

FAN, R. W. (1984): A comparison study of the development of the ovule and embryo sac of clones of Aigeiros poplars. J Nanjing Inst For 3: 44-50.

HaRLAN, J. R. and J. M. J. DEWet (1975): On Ö. Winge and a prayer: the origins of polyploidy. Bot Rev 41: 361-390.

Johnsson, H. and C. EkLundH (1940): Colchicine treatment as a method in breeding hardwood species. Svensk Papp Tidn 43: 373-377.

JoRDAN, M. A. and L. WILsON (1999): The use and action of drugs in analyzing mitosis. Method Cell Biol 61: 267-295.

KANG, X. Y. (2002): Cytogenesis and triploid breeding of Chinese white poplar. China Environmental Science Press, Beijing.

KANG, X. Y. and Z. T. ZHU (1997): A study on the $2 n$ pollen vitality and germinant characteristics of white poplars. Acta Botanica Yunnanica 19(4): 402-406.

KANG, X. Y., Z. T. ZHU and H. B. LIN (1999): Study on the effective treating period for pollen chromosome doubling of Populus tomentosa x P. bolleana. Sci Silvae Sinicae 35(4): 21-24.

KANG, X. Y., Z. T. ZHU and H. B. LIN (2000): Radiosensitivity of different ploidy pollen in poplars and its application. Acta Genet Sinica 27(1): 78-82. 
KANG, X. Y., P. D. Zhang, P. GAO and F. ZhaO (2004): Discovery of a new way of poplar triploids induced with colchicine after pollination. J Beijing For Univ 26(1): $1-4$.

KImURA, C. (1955): The embryo sac of Populus sieboldii Miquel. Sci Rep Tohoku Univ Biol 21: 122-125.

KIMURA, C. (1963): On the embryo sac formation of some members of the Salicaceae. Sci Rep Tohoku Univ Biol 29: 393-398.

LI, W. T. and T. ZHU (1988): Development of pollen and embryo sac in Populus euphratica Oliv. For Res 1(2): 132-139.

LI, W. D. and F. S. MA (2006): Reproductive biology of sexual hybridization in woody plants: an atlas. Science Press, Beijing.

LI, W. T., R. W. FAN and X. L. MAI (1982): On the embryological observations of the seed development of Populus simonii Carr. Sci Silvae Sinicae 18(2): 113-119.

LI, Y. H., X. Y. KANG, S. D. WANG, Z. H. Zhang and H. W. CHen (2008): Triploid induction in Populus alba $\mathrm{x}$ $P$. glandulosa by chromosome doubling of female gametes. Silvae Genet 57(1): 37-40.

Mashkina, O. S., L. M. Burdaeva, M. M. Belozerova and L. N. Vyunova (1989): Method of obtaining diploid pollen of woody species. Lesovedenie 1: 19-25.

Mendiburu, A. O. and S. J. Peloquin (1977): The significance of $2 n$ gametes in potato breeding. Theor Appl Genet 49: 53-61.

NAGARAJ, M. (1952): Floral morphology of Populus deltoids and $P$. tremuloides. Botanical Gazette 114: 222-243.

OGBuRIA, M. N., T. YABUYA and T. ADACHI (2002): A cytogenetic study of bilateral sexual polyploidization in cassava (Manihot esculenta Crantz). Plant Breeding 121: 278-280.

Pfeiffer, T. W. and E. T. Bingham (1983): Abnormal meiosis in alfalfa, Medicago sativa: cytology of $2 n$ egg and $4 n$ pollen formation. Can J Genet Cytol 25: 107-112.
Rae, A. M., N. R. Street and M. Rodríguez-Acosta (2007): Populus trees, pp. 1-28. In: Genome mapping and molecular breeding in plants, vol. 7, Forest trees, edited by C. KoLE, Springer-Verlag, Berlin, Heidelberg.

SANZOL, J. and M. HeRRERo (2001): The "effective pollination period" in fruit trees. Sci Hortic 90(1): 1-17.

van BuiJTEnen, J. P., P. N. JoRAnson and D. W. Einspahr (1958): Diploid versus triploid aspen as pulpwood sources with reference to growth, chemical, physical and pulping differences. Tappi 41(4): 170-175.

VeILleUX, R. E. (1985): Diploid and polyploid gametes in crop plants: mechanisms of formation and utilization in plant breeding. Plant Breeding Rev 3: 253-288.

Werner, J. E. and S. J. PeloqUin (1987): Frequency and mechanisms of $2 n$ egg formation in haploid Tuberosumwild species $\mathrm{F}_{1}$ hybrids. Am Potato J 64: 641-654.

WERNER, J. E. and S. J. PELOQUIN (1990): Inheritance and two medchanisms of $2 n$ egg formation in $2 x$ potatoes. $J$ Hered 81(5): 371-374.

WeRner, J. E. and S. J. Peloquin (1991): Occurrence and mechanisms of $2 n$ egg formation in $2 x$ potato. Genome 34: 975-982.

Winton, L. L. (1968): Fertilization in forced quaking aspen and cottonwood. Silvae Genet 17(1): 20-21.

YAMADA, A. and R. TAO (2007): Controlled pollination with sorted reduced and unreduced pollen grains reveals unreduced embryo sac formation in Diospyros kaki Thunb. 'Fujiwaragosho'. J Japan Soc Hort Sci 76(2): 133-138.

ZHANG, Z. Y. and F. L. LI (1992): The techniques of pollen chromosome doubling of Populus tomentosa. J Beijing For Univ 14(Suppl. 3): 52-58.

ZHU, T. and W. T. LI (1989): Formation and development of the ovule and embryo sac in Populus lasiocarpa Oliver. J Wuhan Bot Res 7(1): 13-20.

ZHU, Z. T., H. B. LIN and X. Y. KANG (1995): Studies on allotriploid breeding of Populus tomentosa B301 clones. Sci Silvae Sinicae 31(6): 499-505. 